\title{
Impact of Demographic Factors on Impulse Buying Behavior: A Study of consumer behavior in Supermarkets of Karachi
}

\author{
Muhammad Abu-Bakr Ali and Shameel Ahmed Zubairi
}

\begin{abstract}
Analysis of consumer behavior needs to be studied in a more holistic way to understand what factors lead consumers to buy on impulse. The primary aim of this study was to determine the influence of demographic factors on the Impulse Buying Behavior (IBB) of the consumers of supermarkets. It was aimed to study the impact of demographic factors (age, gender, and income), on the type of IBB (reminder, pure, suggestion and planned IBB). In this research the quantitative research method was used for analysis and getting the results. The population of this study comprised of consumers in supermarkets situated in Karachi. The samples in this study were those who were shopping at the selected supermarkets in Karachi. Convenience sampling was used to gather the information from 300 respondents. Descriptive analysis, reliability analysis, and regression analysis were executed using SPSS for testing the stated hypothesis of the study. The questionnaire was used as a tool for collecting primary data. The results of the study indicated that the Demographic factors significantly influence pure impulse buying behavior and suggestion impulse buying behavior.

Keywords - Impulse buying behavior; demographic factor; pure Impulse buying behavior; planned Impulse buying behavior; reminder Impulse buying behavior; suggestion Impulse buying behavior.
\end{abstract}

\section{INTRODUCTION}

Analysis of consumer behavior needs to be studied in a more holistic way to understand what factors lead consumers to buy on impulse. In the context of marketing and consumer behavior, several factors have been identified as related to the consumer impulse buying behavior (IBB) and the theme has advanced with the analysis of these factors: family structure, materialism, socialization, demographic aspects, self-esteem, anxiety, and introversion [1] [3] [9].

According to [27] [19] a critical view of consumerism Shopping centers, malls, and supermarkets, can be seen as a trap to capture potential buyers. Another view of this environment is defended by Evangelista who defines supermarkets as an environment capable of meeting the needs and desires of consumers [13]. The supermarkets must also be understood as places of social living. People do not go to the supermarkets just to buy something, but also to stroll and have socializing [24].

The growth of commerce in supermarkets, notably in cities is in development that impacts consumer behavior and in the need to know more about the factors that affect the purchase behavior by impulse. However, although the studies mentioned above have contributed to the literature to identify important variables in this context, there is still the opportunity for integration and an empirical test of the main explanatory factors of the IBB.

As noted by Sohn and Lee IBB has received little attention from researchers, so this research article wishes to contribute to the advancement of knowledge in this area, given the scarcity of national studies reporting factors that influence impulse buying, specifically in a supermarkets environment [23].Based on these considerations, the objective of this work was to propose and test a theoretical model that integrates the main factor that influence the impulse buying behavior (IBB).

\section{PROBLEM STATEMENT}

The evaluation of the existing literature critically related to IBB has indicated that existing research work has been executed focusing on factors or attributes associated with external cues influencing IBB. The research was previously done in different geographic market. therefore, the purpose of the present research work is to check out whether the findings of previous research work are applicable in the market of Karachi through testing the impact of demographic factors on the IBB. The researchers are aiming to look forward that what impact of this factor had been carried out in the market of Karachi. Moreover, previous research work mainly focused on IBB disregarding the type of IBB, the researcher is also aiming to fill out this gap. Therefore, the present research work has a focus that is to determine the impact of demographic factors on impulse buying behavior. having a strong emphasis on four types of IBB including pure IBB, reminder IBB, suggestion IBB and planned IBB.

\section{AIM OF THE RESEARCH}

The primary aim of this study is to explore demographic factors influencing the IBB of the consumers of supermarkets in Karachi. The specific objectives of the study are as follow:

- To study the impact of demographic factors (age, gender, and income) on the type of IBB (reminder, pure, suggestion, and planned IBB) of the consumers of supermarket in Karachi.

\section{RESEARCH HYPOTHESIS}

H1: There is a significant relationship between 
demographic factors and the pure IBB of consumer in supermarkets.

$\mathrm{H} 2$ : There is a significant relationship between demographic factors and the reminder IBB of consumer in supermarkets.

H3: There is a significant relationship between demographic factors and the suggestion IBB of consumer in supermarkets.

H4: There is a significant relationship between demographic factors and the planned IBB of consumer in supermarkets.

\section{Limitations OF THE STUDY}

The current research paper is limited to different aspects that identify the overall scope of the research. The current research work is limited to the process of data collection; Data were collected from consumers of selected supermarkets situated in Karachi Pakistan. Moreover, this research work is also limited to the sample size of the study that is 300 consumers from selected supermarkets of Karachi. Likewise, the current research work is limited to self-administered questionnaires that were used for collecting data from the respondents. Lack of time also served as the limitation of the study that affects not discussing various factors that influence consumer buying behavior including product involvement and availability of time.

\section{JUSTIFICATION OF THE STUDY}

\section{a) Convenience}

Research is convenient because it will be possible to know what those factors influencing consumer behavior when shopping at supermarkets, may be used as a basis for future research Moreover the research will be useful for the companies to increase their sales turnover in integration with the supermarkets

\section{b) Social relevance}

Its relevance to society is important since currently, this type of supermarket has shown great growth and satisfaction of consumers. an acceptance pressure has been built by the society in last few decades which mainly resulted into the growth of the supermarkets.

\section{c) Practical Implications}

The research will identify how factors directly influence consumer purchasing behavior.

\section{d) Theoretical Value}

Research determines the factors that influence the behavior of consumers when they reach the responsibilities of their consumers in the supermarkets. Research can be used for wider use of the target tools. the research can become the basis of targeting the most specific group, which is becoming particular about the shopping pattern

\section{REVIEW OF THE LITERATURE}

\section{A. Impulse buying behavior}

Impulsive buying is a term well known among the business pioneers and academicians of marketing. IBB is known as acquiring goods without having a prior plan or urge if not restricted to a particular good or business setting. Customers'
IBB is shown in the shopping of grocery, apparel, medications, automated equipment, furniture, and ornaments, etc. Moreover, impulsive buying befalls in supermarkets, departmental stores, mini gift shops, book stores, drugstores, and so on. Explaining briefly, IBB is not a limited concept and it does occur regardless of the marketplace. Although the behavior is not restricted to any specific market place, the phenomena are usually studied in supermarkets. The importance of this sort of conduct in this retail situation is perceived by the du Pont study, which indicates that unintended purchasing represents $50 \%$ of the products purchased in food superstores [22]. In this manner, the essentialness of unintended purchasing is extensively acknowledged and recognized [16].

- Planned IBB: An IBB which reflects the elements of rational, planned, accurate, and better decisions unlike pure or spontaneous decisions are called the planned IBB.

- Pure IBB: A sudden urge of buying something, just before you are going to buy your planned product is termed pure IBB. When this behavior is spontaneous, it is known as pure IBB.

- Suggestion IBB: In a store environment different factors influence the buying behavior of a customer, whenever the sudden decision of buying something is made by the customer in the result of the marketing practice made by the concerned person, this type of behavior is known as suggestion IBB.

- Reminder impulse: Whenever the mind of the customer had already come across the product by any means of communication and the customer made this purchase by the influence of that communication, such type is known as the reminder IBB.

\section{B. Demographic Factors}

The demographic classification divides customers into the segments based on analytical principles including age, sex, wages, and education, etc. Kotler and Keller defines that the wants and needs plus the purchasing behavior of a customer keeps varying with time (age) while the rest of the demographic factors like sex, wages, and education, etc. also possess and impact on purchasing habits[14]. According to many prior studies and surveys, demographic variables are related to the sale of many products which make the significance of various demographic factors prominent for the vendors [10].

\section{Empirical Review}

Ekeng, Lifu and Asinya from Nigeria proposed research that studied the impact of demographic characteristics of buyer affecting impulse buying. Data was collected from 400 participants in a marketplace through a questionnaire. Results from the multiple regression uncovered that $88 \%$ of impulse buying was represented by the mix of buyers' statistic qualities [12]. ANOVA result also indicated that the consumers' demographic traits had a strong influence on impulse buying. Pearson's correlation revealed that the age of the consumers was inversely proportional to impulse buying.

Shukla, Banerjee and Adidam presented a study that examined the influence of socio-demographic traits of a customer including gender, age, education, income and 
family size on the relationship between psychographic measures including general deal proneness, price-related deal proneness, end-of-aisle display proneness, impulsiveness, smart-shopper self-perceptions, and brand loyalty and consumers' attitude towards private label brands[21]. Data were collected from 3 British Supermarkets and the results showed a significant impact of deal proneness among highincome consumers, while the strong influence of the end-ofaisle display proneness among older and high-income and highly educated consumers. Moreover, it also presented empirical research on the relationship between impulsiveness and brand attitude among low-income and less-educated consumers.

Choudhary from Indore conducted a conceptual study that overviewed the IBB among consumers and the factors thought to be influential for it. It describes the differences between impulsive and compulsive shopping and also defines personal characteristics like emotion, age, gender, etc. contributing to impulse buying [7]. This paper gives a clear understanding of the concepts and would be useful for both beginners and researchers.

Awan, and Abbas studied the impact of demographic characteristics of buyer affecting impulse buying among consumers in Multan, Pakistan. 104 males and 146 females were approached for the collection of Data. SPSS 17.0 was sued to analyze the data. According to the results of multiple regression and chi-square test results, gender and age were expressively and contrariwise concomitant with IBB of buyers while income and education were directly associated with the IB and ANOVA results indicated that demographic characteristics have a significant impact of IB behavior of consumers[2].

Mathai and Dharmaraj concluded research that studies the impulse buying nature of children in snacks according to the perspective of their parents [17]. TV advertisements were a huge factor influencing IB among children. The results also indicated that Mother's age was has a significant impact on children's IB.

Cakanlar and Nguyen conducted a study that was aimed to observe the influence of culture on IB. Data was collected through a questionnaire distributed cross-culture across Sweden, Turkey, and Vietnam. Results concluded that culture highly impacts the IBB of consumers [6].

Mohiuddin and Iqbal from Karachi, Pakistan studied the impact of demographic characteristics of buyers affecting impulse buying among consumers in Pakistan. The research was based on the secondary data and it concluded that all the factors gender, age, education, etc. have a strong association with IB among consumers in Pakistan [18].

Xu worked on Mehrabian and Russell (1974) S-O-R model and researched to have a deeper understanding of how the environment of a store/shopping place impacts IBB among Generation Y consumers i.e. adult generation [26].The results drastically displayed that generation Y consumers are highly influenced by the store environment. Emotions, inclination, and urge are the factors that influence IBB in a store among these consumers.

Tinne introduced a research paper that discussed the effects of the IBB of consumers in Bangladeshi superstores. A structured questionnaire focusing discounts, deals, promotional activities, limited time offers, window display, an environment of the store, brand consciousness, influence of reference group, income, and festive seasons was conducted among the buyers of Agora and Meena Bazaar. Using SPSS software and factor analysis, the results of the study showed that the buying power of consumers is comparatively gone up than in old times. Pricing strategies, store environment, situational factors, and promotional activities were found to be the main factors influencing impulse buying nature among consumers [25].

\section{The gap in the Literature}

The current review of the literature related to IBB identified different findings considering the impact of demographic factor on buying behavior of consumers. The review of the literature suggests that different research work has been carried out emphasizing on the factors affecting the IBB of the consumers with a skewed emphasis on identifying the impact of a single comprehensive factor on IBB. The factors considered in the existing literature include demographic characteristics This factor although explored by previous researchers, however, there is a lack of integrated comprehensive research work that considered the impact of demographic factors included in a same study. Moreover, it is also identified that research work related to factors affecting impulse buying behavior executed within Karachi Pakistan is limited. There is also a need for exploring the impact of demographic factors on four different types of IBB.

\section{E. Conceptual Framework}

Model developed by the researcher and the visual representation indicate the variables used in the current research work:

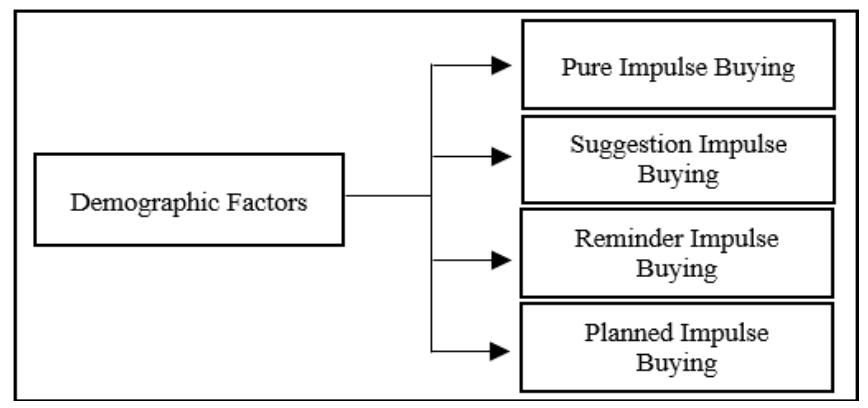

\section{RESEARCH METHODOLOGY}

\section{A. Research Approach}

The origin of this investigation is a deductive approach. It started to build a theoretical-conceptual framework based on the existing academic literature on IBB. Research objectives were formulated, a conceptual model was designed and a hypothesis was defined to be empirically tested. It is intended to explain the phenomenon under study using inference, taking into given the generalization of the results. It will, therefore, be said that this is a study of hypothetical-deductive nature, as it seeks to explain the underlying causes or factors influencing IBB.

\section{B. Research Design}

It is also a study of a correlational nature, whose objective is to infer about the theoretical population, based on a sample of that population, through the identification of relationships between statistical variables [15]. Correlational studies not 
only presuppose the measurement (quantification) of the degree of relationship between two or more variables, equally also measure and analyze correlations, through hypothesis testing [8]. In studies of this nature, the researcher is limited to observing the variables not having any type of purposeful control or intervention over the variables.

\section{Research Method}

For current research work, the quantitative research method has been taken into consideration, hence focusing on testing the hypothesis identified in the previous section. Quantitative research is identified as a method that is based on positivism philosophical underpinning [5]. Positivism philosophy focuses on exploring and assessing a specific sample or the entire population. For conducting quantitative research, samples of the study are selected through a random approach, using quantitative nature research instruments that lead towards conducting statistical analysis for testing the hypothesis [20].

\section{The population of the Study}

The population of this study are consumers in supermarkets situated in Karachi.

\section{E. Sampling Design}

The samples in this study were those who were shopping at the selected supermarkets in Karachi. Convenience sampling was used as the main sampling technique that collects information from members of the population. Convenience sampling allows having easy access to the targeted population and the researcher relies on collecting data from the respondents who are conveniently available for participating in the research process.

\section{F. Data Collection Process}

Data collection techniques in this study are through the use of questionnaires as a tool for collecting primary data. In addition to primary data collection, secondary data sources were also used for collecting secondary information reviewing the existing literature. Different journal articles and peer-reviewed research papers were accessed as main secondary data sources.

\section{G. Instrument}

For facilitating the development of a research instrument for the current research work, 5 points Likert scale was taken into consideration for measuring the variables included in the research. The questionnaire used in this study had two parts. The first part had 5 items on demographics based on the nominal scale. The second part comprised of four constructs that were adapted from the previous literature. The four constructs were based on the five-points Likert scale.

\section{H. Methods of Data Analysis}

In analyzing this data, the researcher did different procedures by grouping data, tabulating data, presenting data, doing calculations, and testing hypothesis through statistics. As for the statistics that are used to analyze the data in this study, namely inferential statistics using descriptive analysis, reliability analysis, and regression analysis

\section{FINDINGS AND ANALYSIS}

\section{A. Introduction}

This section of the study introduces quantitative findings that are attained after collecting data using survey questionnaires. In this section, the profile of respondents who participated in the survey process is discussed; reliability analysis, hypothesis testing, and discussion on these findings are developed.

\section{B. Descriptive Statistics}

The descriptive statistics of the variables are presented in Table 1.

TABLE I: DESCRIPTIVE STATISTICS

\begin{tabular}{lllll}
\hline \hline & Mean & Std.Dev & $\begin{array}{l}\text { Ske } \\
\text { wnes } \\
\mathrm{s}\end{array}$ & Kurtosis \\
\hline Demographics & 4.10 & 1.21 & 1.21 & 1.17 \\
\hline \hline
\end{tabular}

Table 1 shows that Demographic Factors has mean=4.10, $\mathrm{SD}=1.21, \mathrm{SK}=1.21, \mathrm{ST}=1.17$.

\section{Reliability Analysis}

Table 2 shows that The Cronbach Alpha of Demographic Factors is $\alpha=.85$; that means it has a meaningful intercorrelation (or also called internal consistency).

\begin{tabular}{ll} 
TABLE II: RELIABILITY ANALYSIS \\
\hline \hline $\begin{array}{l}\text { Cronbach } \\
\text { Alpha }\end{array}$ \\
\hline Demographic & .85 \\
\hline \hline
\end{tabular}

\section{Characterization of the sample}

The characterization of the researched sample was based on the identification of socio-demographic data. Frequency analysis was executed analyzing the gender, monthly income, age, education, and region of the respondents who participated in the survey process. The data were analyzed descriptively and arranged in a table to facilitate visualization. According to the findings, it is identified that the average age of the respondents who participated in the survey was 32 years, with the youngest age at 18 years and the oldest at 65 . The age group between 20 and 40 years old showed a predominance of respondents, confirmed by the median and representing more than $2 / 3$ of the respondents who participated. However, the visits to supermarkets and having IBB by different age groups are already a reality. This characterization is confirmed by the study of Desai and Mistry, who considers the age group between 18 to 35 years old, like that of greater predominance for the IBB [11].

Regarding the gender of the respondents, a prevalence was observed for the female, who represented $65.67 \%$ of the sample, about the male who represents $34.33 \%$ ) Regarding the frequency of visiting supermarkets, $88 \%$ of respondents point out that the visiting supermarkets are part of their routines, $55 \%$ say they use it frequently and another 33\% say they rarely visit supermarkets. This frequency in visiting supermarkets may be associated with what Rahman \& Samiha (2019) who attribute the increased frequency of access to supermarkets is related in the context of home 
improvement, improved transportation, and availability of diverse items in one place.

Regarding the subjects' monthly income, the sample was characterized by a certain balance for the first two bands, where $24.33 \%$ declared to have income less than 15000PKR and $21 \%$ reported that monthly they receive an amount between $15,000 \mathrm{PKR}$ to $30,000 \mathrm{PKR}$. The range with the highest number of respondents was the third range, with $37 \%$ of subjects declaring that they received a monthly income of $31,000 \mathrm{PKR}$ to $50,000 \mathrm{PKR}$. The fourth and fifth bands combined contributed $17 \%$ of the survey respondents.

The subjects who participated in our sample were asked in which region of the Karachi city they lived, it was characterized that the majority of participants reside in the Central District of Karachi. 95\%, in the Central District, $2.33 \%$ of respondents of the South District contributed, and $1.67 \%$ of the North had $0.33 \%$ of District East of Karachi participated, $0.67 \%$ of our sample residing outside of Karachi as shown. reflection of the collected data from the sample can be observed in the findings of the results.

Regarding the degree of education of the group participating in the sample, characterization was established with a predominance of post-graduate individuals $45.33 \%$, followed by individuals with complete higher education $24.00 \%$ others $25.33 \%$ of subjects who are in higher education. Together these three groups of respondents reached a percentage of $94.66 \%$ of subjects already enrolled in studying higher education, completed it, or have already passed these stages and is a graduate, this fact refers to a characterization of the group with a high level of education, which allows us to deduce that they are individuals aware of their role in society and of the benefits of participating in research and contributing with answers that infer a reality.

\section{E. Regression Analysis}

Regression Analysis was executed using SPSS for testing the stated hypothesis of the study. The following are the results of the Regression test for identifying the impact of demographic factors on pure, planned, suggestion, and reminder IBB. IBB

Relationship between demographic factors and types of

The first hypothesis examines the relationship between demographic factors and pure IBB. The results of simple regression analysis are presented in Table 3 for the first hypothesis that is: "There is a significant impact of demographic factors on the pure IBB of consumers in supermarkets."

TABLE III: RESULTS HYPOTHESIS 1

\begin{tabular}{llllll}
\hline \hline & $\mathrm{R}^{2}$ & $\begin{array}{l}\text { Adjusted } \\
\mathrm{R}^{2}\end{array}$ & $\mathrm{~F}$ & $\mathrm{~B}$ & $\mathrm{Sig}$ \\
\hline $\begin{array}{l}\text { Demographics } \\
\text { Factors }\end{array}$ & 0.312 & .278 & 65.089 & 0.244 & 0.004 \\
\hline \hline
\end{tabular}

The results suggested that the hypothesis testing the impact of demographic factors on pure IBB was accepted. Demographic factors explain $27.8 \%$ of the variance in pure IBB. The Adjusted R2 $=.278, \mathrm{~F}=65.089, \mathrm{p}<0.05$. Thus, Demographic factors $(\beta=0.244, \quad \mathrm{p}<.05)$ significantly influences pure IBB.
The second hypothesis examines the impact of demographic factors and reminder IBB. The results of simple regression analysis are presented in Table 4 for the second hypothesis that is: "There is a significant impact of demographic factors on the reminder IBB of consumers in supermarkets."

\begin{tabular}{llllll}
\multicolumn{5}{c}{ TABLE IV: RESULTS HYPOTHESIS 2 } \\
& $\mathrm{R}^{2}$ & $\begin{array}{l}\text { Adjusted } \\
\mathrm{R}^{2}\end{array}$ & $\mathrm{~F}$ & \multirow{3}{*}{$\mathrm{S}$} & \\
& & & & \\
\hline $\begin{array}{l}\text { Demographics } \\
\text { Factors }\end{array}$ & 0.480 & 0.177 & 178.10 & 0.693 & 0.238 \\
\hline \hline
\end{tabular}

The results suggested that the hypothesis testing the impact of demographic factors on reminder IBB was rejected. Demographic factors explain $17.7 \%$ of the variance in reminder IBB. The Adjusted R2 $=.480, \mathrm{~F}=178.10, \mathrm{p}>0.05$. Thus, Demographic factors $(B=.693, \mathrm{p}>.05)$ does not significantly influences reminder IBB.

The third hypothesis examines the impact of demographic factors and suggestion IBB. The results of simple regression analysis are presented in Table 5 for the third hypothesis that is: "There is a significant impact of demographic factors on the suggestion IBB of consumers in supermarkets." TABLE V: RESULTS HYPOTHESIS 3

\begin{tabular}{llllll}
\hline \hline & $\mathrm{R}^{2}$ & $\begin{array}{l}\text { Adjusted } \\
\mathrm{R}^{2}\end{array}$ & $\mathrm{~F}$ & $\beta$ & $\mathrm{Sig}$ \\
\hline $\begin{array}{l}\text { Demographics } \\
\text { Factors }\end{array}$ & 0.215 & .219 & 54.052 & 0.244 & 0.004 \\
\hline \hline
\end{tabular}

The results suggested that the hypothesis testing the impact of demographic factors on suggestion IBB was accepted. Demographic factors explain $21.5 \%$ of the variance in reminder IBB. The Adjusted $\mathrm{R} 2=.219, \mathrm{~F}=54.052, \mathrm{p}>0.05$. Thus, Demographic factors $(\beta=.468, \mathrm{p}>.05)$ significantly influences suggestion IBB.

The fourth hypothesis examines the impact of demographic factors and planned IBB. The results of simple regression analysis are presented in Table 6 for the fourth hypothesis that is: "There is a significant impact of demographic factors on the planned IBB of consumers in supermarkets."

\begin{tabular}{llllll}
\multicolumn{5}{c}{ TABLE VI: RESULTS HYPOTHESIS 4 } \\
\hline \hline & $\mathrm{R}^{2}$ & $\begin{array}{l}\text { Adjusted } \\
\mathrm{R}^{2}\end{array}$ & $\mathrm{~F}$ & \multirow{2}{*}{$\mathrm{Sig}$} \\
\hline $\begin{array}{l}\text { Demographics } \\
\text { Factors }\end{array}$ & 0.66 & .662 & 377.99 & 0.244 & 0.353 \\
\hline \hline
\end{tabular}

The results suggested that the hypothesis testing the impact of demographic factors on planned IBB was rejected. Demographic factors explain $66.0 \%$ of the variance in planned IBB. The Adjusted R2 $=.662, \mathrm{~F}=377.99, \mathrm{p}<0.05$. Thus, Demographic factors $(\beta=.814, \mathrm{p}>.05)$ does not significantly influences planned IBB.

\section{Discussion}

\section{A. Impact of Demographic Factors on Pure and Suggestion IBB}

According to the findings of the study indicated that there is a significant impact of demographic factors like age, income, and gender on IBB. The findings of the study are also consistent with the study conducted by [12] [21] and [7]. These authors indicated that gender, income, nd age as a 
demographic factor significantly impact the IBB. Although the findings of the previous study supported the significance of demographic for IBB, however, no study indicated the particular type of impulse buying behavior affected by demographic factors.

This research study expands the prior knowledge base by identifying that demographics factors are more associated with pure and suggestion IBB. Pure impulse buying occurs when a product provokes emotions that lead to the act of buying. It can be contemplated that demographic factors like gender, income, and age may influence the buying behavior of consumers and provokes them to have unplanned buying, based on their emotions. A research work conducted by Shukla, Banerjee and Adidam indicated that high-income consumers, older consumers are highly associated with IBB [21].

On the other hand, it is also identified that demographics factors like gender, income, and age are also significantly associated with suggestion IBB. Suggestion impulse buying occurs when the consumer on seeing the item detects a need that can be satisfied. It is contemplated in this research study that demographic factors significantly influence consumer buying behavior and provokes more impulsive buying. There are four main reasons associated with suggestion impulse buying that include cheap prices of the product, attractive design of the product, new to the consumers and consumers consider products for satisfying an unplanned need [11] [4]. It is contemplated in this research study that demographic factors stimulate suggestion IBB in consumers and have unplanned purchasing to satisfy their needs.

\section{CONCLUSION}

The primary aim of this study is to explore demographic factors influencing the IBB of the consumers of supermarkets. It was aimed to study the impact of demographic factors (age, gender, and income), on the type of IBB (reminder, pure, suggestion, and planned IBB).

In this research, the quantitative research method was used for conducting research. The population of this study comprised of consumers in supermarkets situated in Karachi. The samples in this study were those who were shopping at the selected supermarkets in Karachi. Convenience sampling was used as the main sampling technique that collects information from members of the population. Data collection techniques in this study were the use of questionnaire as a tool for collecting primary data. In analyzing this data, the researcher did a number of procedures by grouping data, tabulating data, presenting data, doing calculations, and testing hypotheses through statistics. As for the statistics that are used to analyze the data in this study, namely inferential statistics using descriptive analysis, reliability analysis, and regression analysis was executed using SPSS for testing the stated hypothesis of the study.

The results suggested that the hypothesis testing the impact of demographic factors on pure IBB was accepted. Demographic factors explain $27.8 \%$ of the variance in pure IBB. The Adjusted R2 $=.278, F=65.089, p<0.05$. Thus, Demographic factors $(B=0.244, \mathrm{p}<.05)$ significantly influences pure IBB. The results suggested that the hypothesis testing the impact of demographic factors on suggestion IBB was accepted. Demographic factors explain $21.5 \%$ of the variance in reminder IBB. The Adjusted R2 $=.219, \mathrm{~F}=54.052, \mathrm{p}>0.05$. Thus, Demographic factors $(ß=$ $.468, \mathrm{p}>.05$ ) significantly influences suggestion IBB.

\section{MANAGERIAL IMPLICATIONS}

Purchases without a plan made by consumers contributed to the increase in the company's sales volume. This shows that marketers must be able to stimulate/improve impulse buying decision making using a variety of marketing strategies. The results of research conducted on modern business consumers at Supermarkets are known to improve consumer purchase decision making. Purchases without a plan can be influenced by providing stimuli to the positive response of consumers to improve the characteristics of the shop environment and pay attention to situational factors. Marketers can implement several types of marketing strategies so that the company's goal may to increase purchases without plans by consumers remains higher.

Ways that can be done to improve the stimuli affecting IBB may include financial capabilities increasingly high will cause consumers to behave more impulsively. In general, consumers have more money at the date of getting salary or pocket money. At that moment it is a good time to stimulate consumers to shop more impulsively and to increase consumer spending in the retail business or increase purchases without a plan.

\section{RESEARCH LIMITATIONS}

In this study, the authors have a limitation that is not grouping or using the type or size of stores with the same characteristics. This condition will certainly differ in the level of impulsive shopping behavior from each consumer from a particular store. It certainly will affect the magnitude of outcomes (impulsive shopping behavior) and the results can be used to predict type of impulsive shopping behavior in the supermarket.

\section{Suggestions For UpCOMING Research}

The author recommends similar research in the future to research retail businesses or fashion industry that test different impulsive spending behavior from each store. This is done to know the differences in levels of impulsive shopping behavior based on stimuli performed by each.

\section{ACKNOWLEDGMENT}

First of all, I would like to express my gratitude to almighty ALLAH who gave me strength to take this thesis to a successful completion and within the prescribed time. My sincere gratitude to my research supervisor Dr. Shameel Ahmed Zubairi for his valuable advice insight and guidance starting from proposal development to the completion of this thesis by devoting his precious time and effort. I want to thank my institute Karachi University Business School (KUBS) for giving me enough knowledge ability and confidence to work on this thesis.

Special love and thanks to my father, my mother and extended family who have showed me unconditional love and support throughout my journey.

In conclusion, I would like to thanks my friends, wellWishers and I am truly grateful for each and every person associated with my research and supported me in the fulfillment of my research work. 


\section{REFERENCES}

[1] Amos, C., Holmes, G. R., \& Keneson, W. C. (2014). A meta-analysis of consumer impulse buying. Journal of Retailing and Consumer Services, 21(2), 86-97.

[2] Awan, A. G., \& Abbas, N. (2015). Impact of demographic factors on impulse buying behavior of consumers in Multan-Pakistan. European Journal of Business and Management, 7(22), 96-105.

[3] Badgaiyan, A. J., \& Verma, A. (2015). Does urge to buy impulsively differ from impulsive buying behaviour? Assessing the impact of situational factors. Journal of Retailing and Consumer Services, 22, 145-157.

[4] Brodén, A., \& Söderberg, C. (2011). Impulse buying, reasons why, consumer electronics, Oh my!.

[5] Bryman, A. (2017). Quantitative and qualitative research: further reflections on their integration. In Mixing methods: Qualitative and quantitative research (pp. 57-78). Routledge.

[6] Cakanlar, A., \& Nguyen, T. (2019). The influence of culture on impulse buying. Journal of Consumer Marketing.

[7] Choudhary, S. (2014). Study of impulse buying behavior of consumers. International Journal of Advance Research in Computer Science and Management Studies, 2(9), 1-4.

[8] Curtis, E. A., Comiskey, C., \& Dempsey, O. (2016). Importance and use of correlational research. Nurse Researcher, 23(6).

[9] Darrat, A. A., Darrat, M. A., \& Amyx, D. (2016). How impulse buying influences compulsive buying: The central role of consumer anxiety and escapism. Journal of Retailing and Consumer Services, 31, 103108.

[10] de Wijk, R. A., Maaskant, A. M., Kremer, S., Holthuysen, N. T., \& Stijnen, D. A. (2018). Supermarket shopper movements versus sales and the effects of scent, light, and sound. Food Quality and Preference, 70, 32-39.

[11] Desai, P., \& Mistry, S. H. (2017). A Study Of Influence Of Demographic Factors On Consumer Impulse Buying Behaviour. Sankalpa, 7(1), 35-42.

[12] Ekeng, EA, Lifu, F., \& Asinya, F. (2012). Effect of demographic characteristics on consumer impulse buying among consumers of Calabar municipality, cross river state. Academic Research International , 3 (2).

[13] Evangelista, F. L. G. F. (2017). The impact of new trends in supermarket environment: the case of the olive oil sector (Doctoral dissertation).University Press.

[14] Kotler, P., \& Keller, K. L. (2016). Marketing Management, New Jersey: Pearson Pretice Hall.

[15] Lau, F. (2017). Methods for Correlational Studies. In Handbook of eHealth Evaluation: An Evidence-based Approach [Internet]. University of Victoria.

[16] Martínez-Ruiz, M. P., Blázquez-Resino, J. J., \& Pino, G. (2017). Store attributes leading customer satisfaction with unplanned purchases. The Service Industries Journal, 37(5-6), 277-295.

[17] Mathai, S. T., \& Dharmaraj, A. (2017). A Study on the Parent's Perspective Regarding the Impulse Buying behaviour of Children in Retail Outlets of Cochin City with Special Reference to Snacks. International Journal of Research in Arts and Science, 3(Special Issue Special Issue), 26-28.

[18] Mohiuddin, Z. A., \& Iqbal, H. (2018). Relationship of Demographic Factors and Impulse Buying Behavior of Customers in Pakistan.

[19] Park, S. (2016). What attracts you to shopping malls?: the relationship between perceived shopping value and shopping orientation on purchase intention at shopping malls in suburban areas. In Celebrating America's Pastimes: Baseball, Hot Dogs, Apple Pie and Marketing? (pp. 663-669). Springer, Cham.

[20] Queirós, A., Faria, D., \& Almeida, F. (2017). Strengths and limitations of qualitative and quantitative research methods. European Journal of Education Studies.

[21] Shukla, P., Banerjee, M., \& Adidam, P. T. (2013). The moderating influence of socio-demographic factors on the relationship between consumer psychographics and the attitude towards private label brands. Journal of Consumer Behaviour, 12(6), 423-435.

[22] Sibarani, M., \& Putra, K. K. (2019, July). Determining the value driver of value-based management using Du Pont extended formula in retail companies in digital marketing era. In Global Competitiveness: Business Transformation in the Digital Era: Proceedings of the First Economics and Business Competitiveness International Conference (EBCICON 2018), September 21-22, 2018, Bali, Indonesia (p. 113). Routledge.

[23] Sohn, H. K., \& Lee, T. J. (2017). Tourists' impulse buying behavior at duty-free shops: The moderating effects of time pressure and shopping involvement. Journal of Travel \& Tourism Marketing, 34(3), 341-356
[24] Terblanche, N. S. (2018). Revisiting the supermarket in-store customer shopping experience. Journal of Retailing and Consumer Services, 40, 48-59.

[25] Tinne, W. S. (2011). Factors affecting impulse buying behavior of consumers at superstores in Bangladesh. ASA University Review, 5(1), 209-220

[26] Xu, Y. (2007). Impact of store environment on adult generation Y consumers' impulse buying. Journal of Shopping Center Research, 14(1), 39-56.

[27] Yamoah, F. A., Duffy, R., Petrovici, D., \& Fearne, A. (2016). Towards a framework for understanding fairtrade purchase intention in the mainstream environment of supermarkets. Journal of business ethics, 136(1), 181-197.

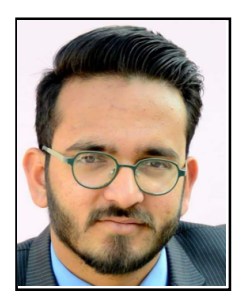

Muhammad Abu-bakr Ali citizen of Karachi, Pakistan. Born in 20th October 1994, is an enthusiastic individual dedicating his efforts in the field of Marketing. He has done MBA in Marketing from Karachi University Business School, University of Karachi. Karachi, Pakistan, 2019. Previously completed his BS in Business Administration from Karachi University Business School, University of Karachi. Karachi, Pakistan, 2017.Mr. Muhammad Abu-Bakr Ali is specialist of B2B Sales and Currently working as a Corporate Sales Executive at Limton Group of Companies in Karachi, Pakistan. 